\title{
Analysis of the influence of design and operating parameters on pressure pulsations in centrifugal pumps
}

\section{Analyse de l'influence de la conception et de l'exploitation des paramètres sur les pulsations de pression dans les pompes centrifuges}

\author{
by $\mathrm{S}$. Timouchev \\ Intellectual Reserves, Moscow Region
}

G. Pavic ( $\left.{ }^{1}\right)$

CETIM

Les pulsations de pression à la fréquence de passage des aubes, causées par l'interaction hydrodynamique instable entre l'écoulement de la roue et l'enveloppe de la volute de la pompe, comportent une composante "pseudo acoustique " et une acoustique.

La première composante vient du mouvement vortex incompressible du liquide et ne se propage pas dans le circuit de la pompe. En général, ce type de pulsation existe effectivement près de la sortie de la roue à une distance radiale d'environ $10 \%$ du rayon de la roue et dans une zone locale près de l'avant-bec. La deuxième composante est une onde acoustique générée par un courant instable. Cette composante dépend des conditions de frontière et impédance à la sortie de l'enveloppe de la pompe et sur la volute et les murs de diffusion.

Cet article fournit quelques résultats informatiques concernant les effets de la géométrie de la pompe et des conditions aux frontières et d'impédance, sur les pulsations de pression.

\section{G GOVERNING EQUATIONS}

The blade-passing frequency (BPF) pulsations are described by the following acoustic-vortex wave equation relative to enthalpy oscillations

where :

$$
\Lambda^{2} \frac{\partial^{2} h}{\partial \tau^{2}}-\nabla^{2} h=s,
$$

$\Lambda=\frac{u_{2} z_{l}}{2 \pi \mathrm{a}}-$ relative blade passing frequency,

$h=\left(H+H_{a}\right) \approx \frac{\rho-\rho_{0}}{\rho u_{2}^{2}}-$ enthalpy (pressure) pulsation,

$H$ - «pseudo sound " pulsation,

$H_{a}$ - acoustic pulsation.

$s$ - source function which depends on the velocity field of vortex incompressible flow.

By using a local specific acoustic impedance $Z$ (complex value), the boundary condition can be put in the form :

$$
\frac{\partial(h-H)}{\partial n}=-\frac{\Lambda}{Z} \frac{\partial(h-H)}{\partial \tau}
$$

(1) Since $01 / 98$ : INSA Lyon.

\section{D HARMONY : A CODE FOR PRESSURE PULSATION COMPUTATION}

The code Harmony [2] has been developed to serve as a user-friendly tool in the analysis of pressure pulsations within a centrifugal machine. It is a two-dimensional representation of the machine with the following features:

- computation of absolute pressure pulsations and hydraulic forces acting on the casing,

- computation of the unsteady pressure field in the working cavity,

- optimization of the geometry (impeller, volute and dif-

fuser) under a given operation mode,

- analysis of centrifugal impeller flow,

- prediction of the acoustic impedance effect on pressure pulsation within the working cavity.

In order to make computations more time-efficient, several simplifying hypotheses were applied :

- the flow is considered isentropic and subsonic,

- the fluid is considered homogeneous and viscous diffusion

is neglected,

- the impeller flow is considered as axisymmetric.

The overall numerical procedure splits into 5 main steps which optimize the computation time and memory required : - boundary condition for the vortex mode at the pump volute inlet. 
- impedance boundary condition at the inlet and exit sections of the pump casing, - incompressible flow (vortex mode) computation in a pump casing,

- source function computation (the right part of the main acoustic-vortex equation),

- solution of the main acoustic-vortex equation which is a non-uniform wave equation.

Definition of boundary condition for the vortex mode includes centrifugal impeller flow computation with $2 \mathrm{D}$ « discrete-vortex method" and subsequent determination of flow parameters at the impeller exit. Vortex mode and wave equations are solved on a 2dimensional polar grid exponentially transformed with non-stationary finite-

difference method. The vortex mode solver has the first time order upwind scheme for advection step and a fast direct procedure for solving the Poisson's equation. The wave equation is solved with the second time order direct procedure with the specified impedance boundary conditions for each harmonic of the blade passing frequency.

Efficient computational algorithms and original pre-processing and post-processing procedures provide an efficient environment for design optimization. A typical task can be computed within one day on a PC.

The applicability of computation is limited to :

- centrifugal pumps or ventilators with specific speed $40<n_{s}<150$ under normal operation mode where $n_{s}=193.3 \omega \sqrt{Q} H^{-3 / 4}$,

- normal operation mode guarantees the accuracy of computation 1.0-2.0 dB,

- delivery range $0.8-1.1$ of the rated value.

Geometry may include arbitrary impeller blade profiles (additional short blades are also permissible) and arbitrary volute-diffuser geometry with one outlet pipe.

The interface for determination of impedance boundary conditions gives a possibility to take into account the connected hydraulic circuit. It includes :

- direct impedance definition for each computed harmonic of the blade passing frequency,

- « open-end » condition,

- « infinite pipe" condition,

- finite-length pipe with various end conditions,

- orifice.

The new version of the code is under development which will include the bladed diffuser.

\subsection{Interface options}

Harmony provides a user friendly interface for the impedance data input including a possibility to add optional or user-defined devices or define the impedance directly for each harmonic.

On figure 1 Harmony interface dialog shows these possibilities for an exit impedance condition. There is a list of standard pre-defined devices such as infinite pipe, pipe without flange, pipe with flange, output into tank, pipe with conical device, pipe with fair device, restrictor, pump (open-end-condition). Outlet Geometry Window contains graphic images of all of devices added to display the outlet chain.
Each standard device impedance, as shown for the restrictor on figure 2, can be defined by geometry and other data input or with direct impedance input (see fig. 3). In the last case one should enter real and imaginary part of a complex specific impedance for each harmonic order.

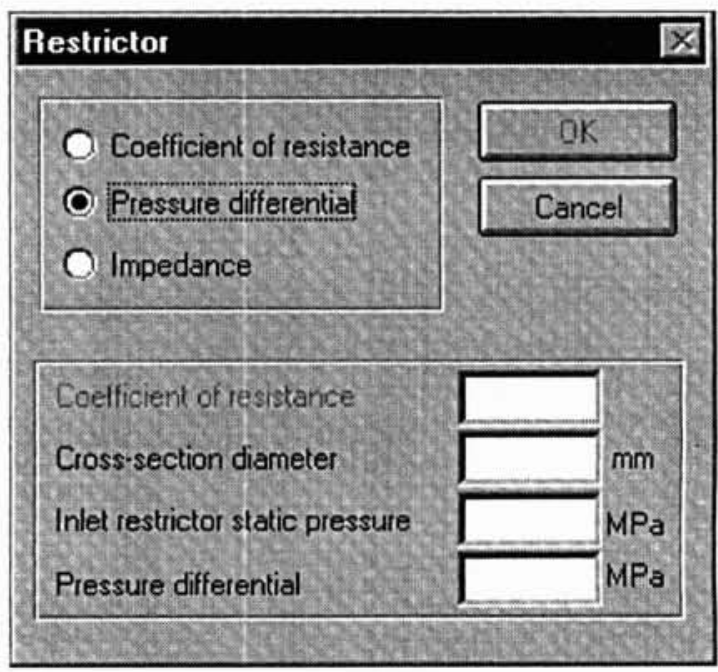

2. Definition of a restrictor impedance.

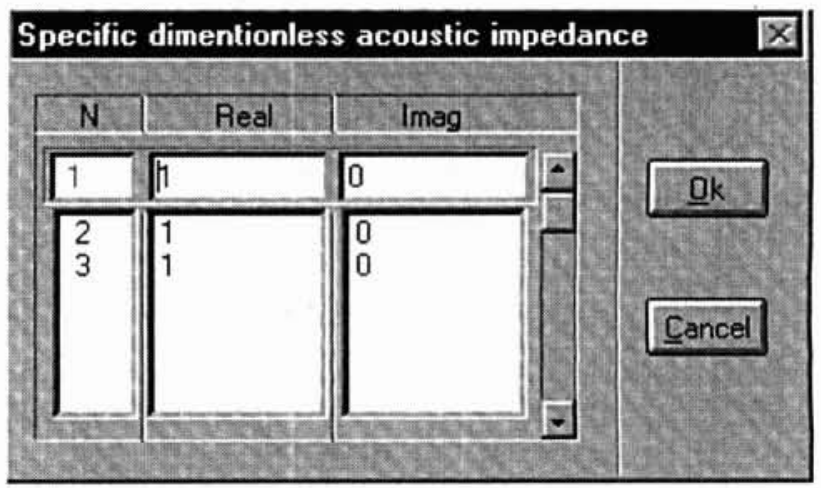

3. Direct impedance input. 
There is a useful possibility to add a new device and specify the device's properties, such as the name of the device, a bitmap that Harmony uses to represent the device, and some geometry and impedance data (see fig. 4).

Experience shows that the pressure pulsation in the pump cavity does not depend on the inlet pipe chain and the inlet impedance can be evaluated from the pump geometry only. Probably this conclusion can be corrected in case of an acoustic resonance in the inlet pipe.

There is another possibility that can be easily utilised in Harmony numerical procedure. This is a definition of local wall impedance to study effects of damping coating.

\section{III — OPEN-END-CONDITION. COMPARISON WITH EXPERIMENTAL DATA}

A centrifugal air pump model of CETIM [3] was used for Harmony validation. Experimental data and computation data were obtained for open-end-condition at the pump exit under following conditions. Number of measuring points in the volute $>300$. Number of finite-difference mesh nodes for the impeller channel span -12 . Number of overall mesh nodes $>10,000$. Time of computation on a PC $100 \mathrm{MHz}$ processor -6 hours. Solution of wave equation for 7 harmonics of main BPF -1.5 hours. RPM -1400 . Delivery $-0.0139 \mathrm{~m}^{3} / \mathrm{s}$.

In the spectrum there are three main harmonics of blade passing frequency. On figure 5 and figure 6 there is a comparison of amplitude maps (computed and measured) for the first harmonic of blade passing frequency.

The characteristic feature of unsteady pressure in the pump volute is lower pressure zones at blade exit edges and

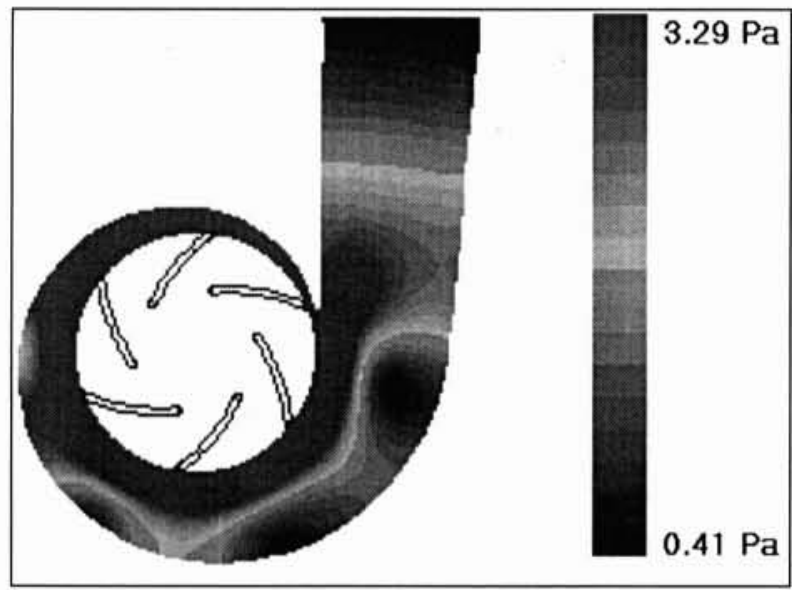

5. Map of the first harmonic amplitude (Harmony computation).

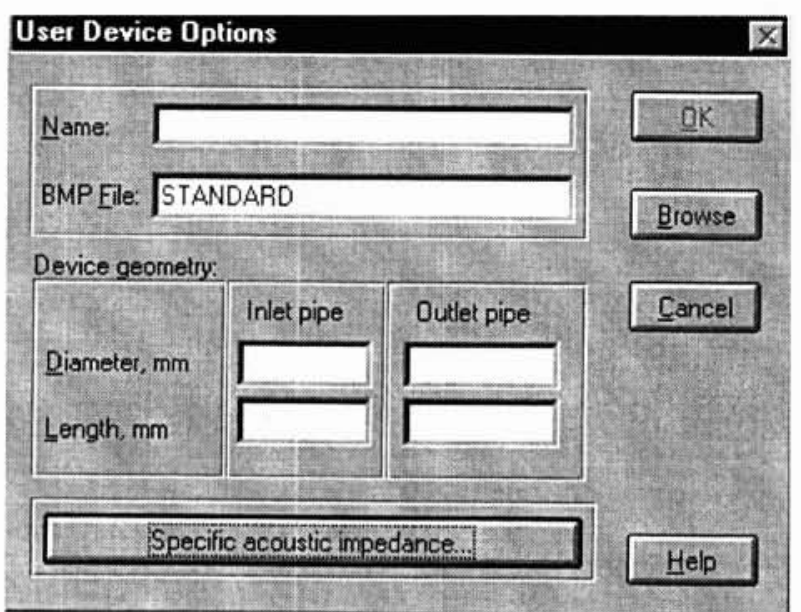

4. User defined device.

rotating with the impeller. Harmony computation also shows such zones. Furthermore, the pressure amplitudes stand in good agreement with the experimental data. The mismatch is mostly below $2 \mathrm{~dB}$.

In the spectrum there are three main harmonics of blade passing frequency. On figure 5 and figure 6 there is a comparison of amplitude maps (computed and measured) for the first harmonic of blade passing frequency.

Such agreement in amplitude map gives a possibility to gain as a right amplitude as a shape of the pressure signal. On figure 7 and figure 8 the computed and measured pressure signals at a point in the volute are shown. Open-endcondition at the diffuser exit enforces pressure pulsation resonance on the third harmonic of blade passing frequency.

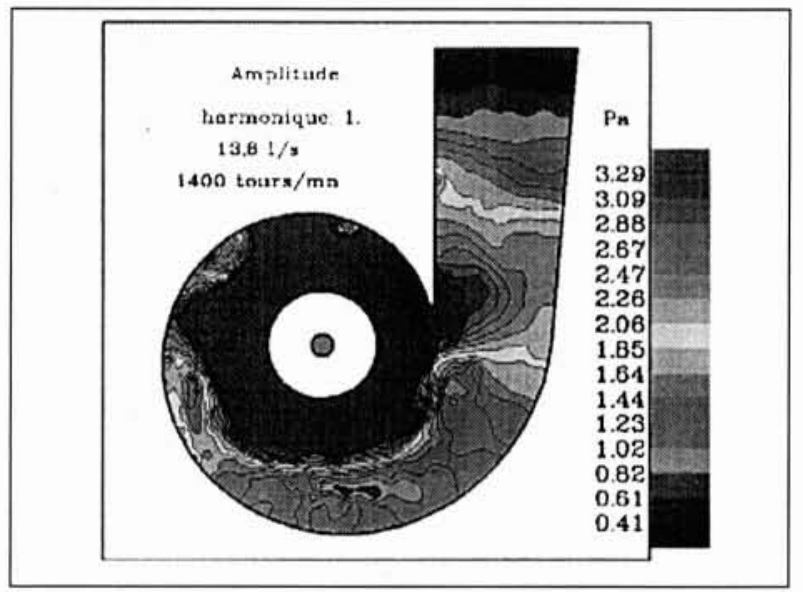

6. Map of the first harmonic amplitude (experiment).

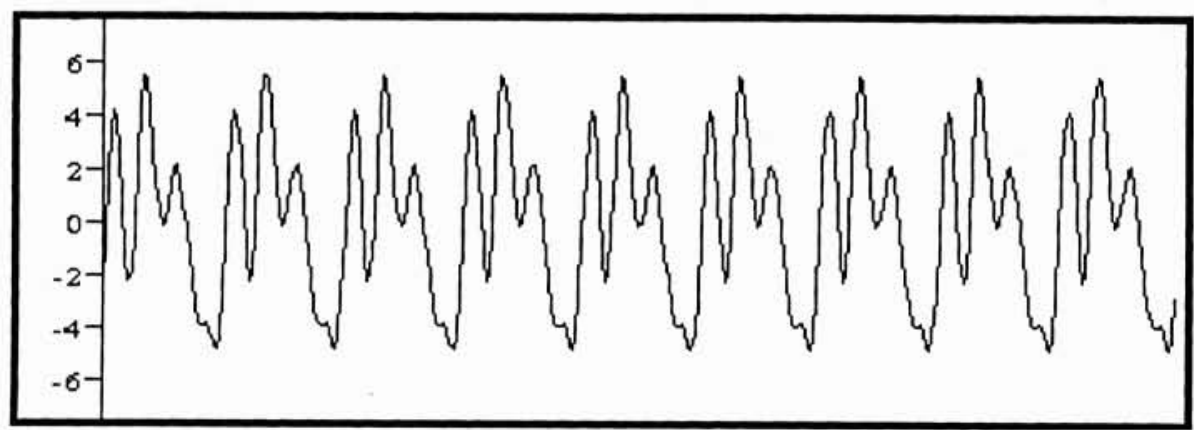

7. Pressure pulsations in the volute $[\mathrm{Pa}]$ : Harmony computation. 


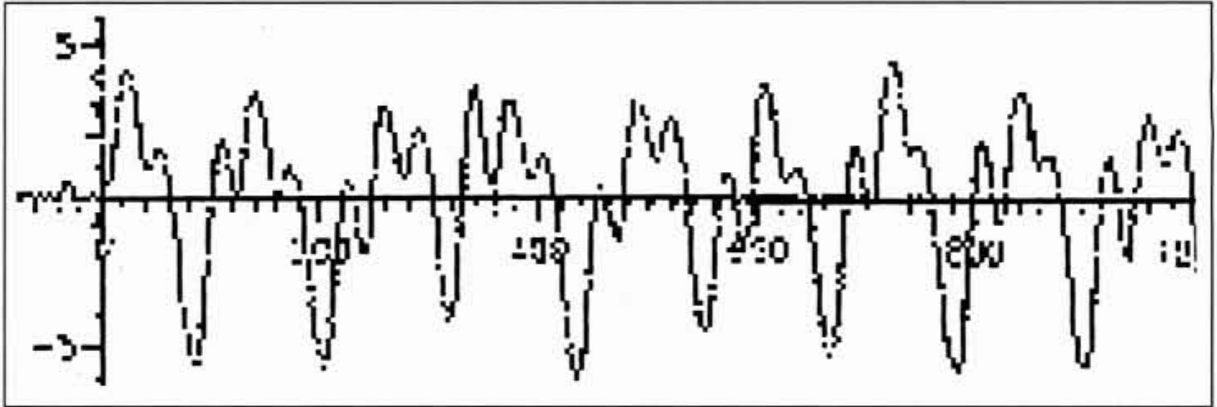

8. Pressure pulsations in the volute $[\mathrm{Pa}]$ : experiment.

\section{IV — EXIT IMPEDANCE EFFECT. COMPUTATIONAL PREDICTION}

The same pump was analysed for the case of an infinite exit pipe to determine the exit impedance effect on pressure pulsation within pump working cavity. It was found that in the most part of the volute exit impedance practically did not affect the pulsation amplitude. Near the volute throat pulsation had almost the same amplitude but a different shape of the signal as it can be seen from figure 9 .

The biggest difference between these two cases can be found certainly at the pump exit (fig. 11), where a considerable difference could be seen in both the amplitude and the shape of signals.

\section{LOCAL WALL IMPEDANCE EFFECT. COMPUTATIONAL PREDICTION}

A computational study was undertaken to see a qualitative

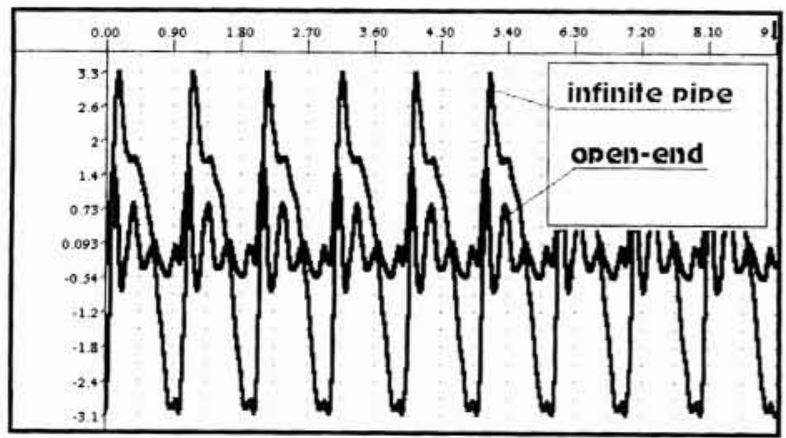

9. Computed pressure pulsation in the volute throat section of air pump model.

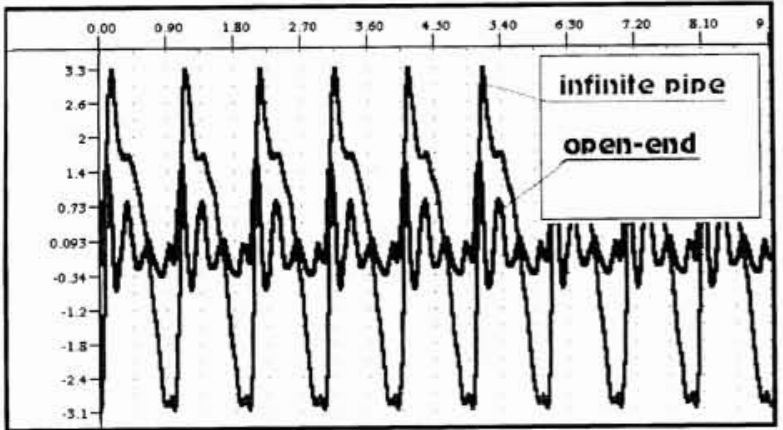

11. Computed pressure pulsation at the air pump exit. effect of damping coating of conical diffuser wall for the centrifugal pump LPRE RD180 [4].

Local wall complex specific impedance was defined by :

$$
Z=15-i(1.5 N \Lambda)
$$

where $\Lambda$ is a relation of impeller radius to main BPF wave length and $N$ - harmonic number. Computation was made for 4 harmonics of the main blade passing frequency.

As the coating with complex impedance placed only into the conical diffuser this practically did not affect pressure pulsation amplitude into the volute until the throat domain where the effect is not considerable as one can see on the figure 13.

Middle section of the conical diffuser is more influenced by the wall coating. It resulted in more then 2 times factor of reduction of pressure pulsation amplitude as shown on figure 12.

The largest effect of coating on the pressure pulsation amplitude was found at the pump exit. It resulted in a reduction of more then 3 times of amplitude as shown on figure 14.

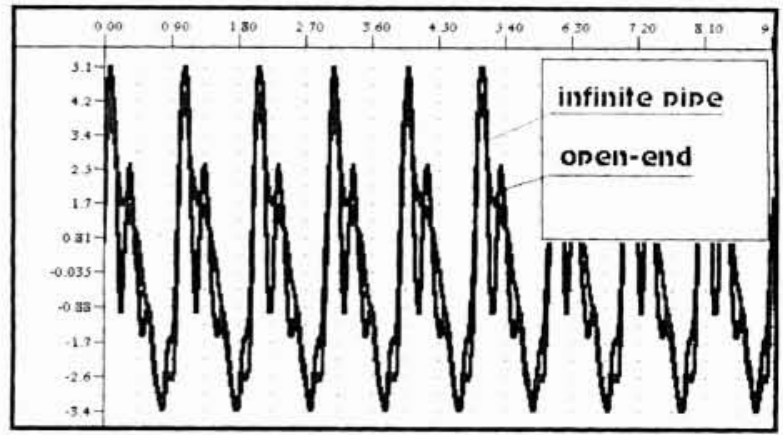

10. Computed pressure pulsation in the volute throat section of air pump model.

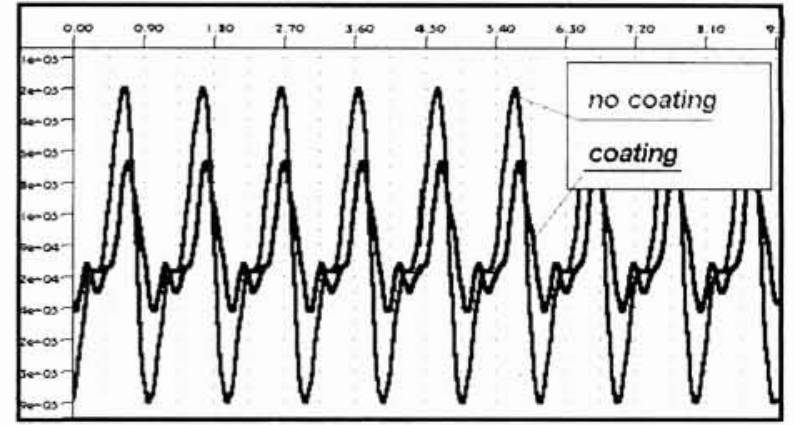

12. Coating effect in the middle section of conical diffuser. 


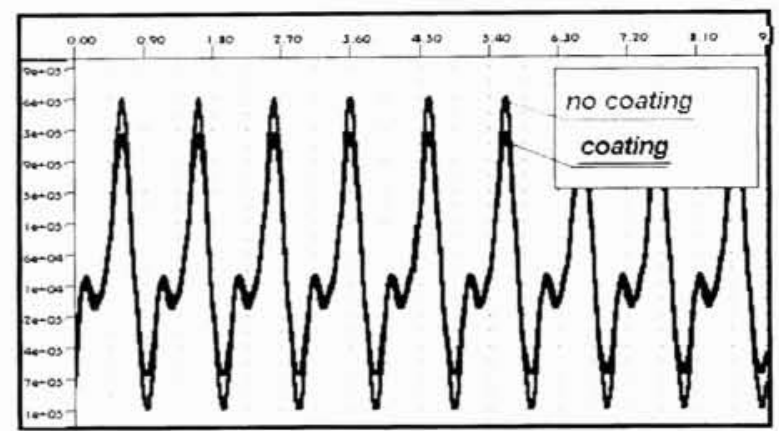

13. Coating effect in the volute throat.

\section{VI — DYNAMIC LOADING}

The dynamic loading of a centrifugal machine exerted by the flowing fluid depends much on its geometry. The loading was analysed for a water pump of $240 \mathrm{~m}^{3} / \mathrm{h}$ delivery at 1200 RPM. figure 15 shows the computed pressure pulsation distribution for the first-harmonic amplitude of this pump.

Figures 16 and figures 17 show the computed dynamic loading acting on the cutwater for three values of spacing between the impeller exit and the cutwater edge : $20 \mathrm{~mm}$ (reference value), 10 and $4 \mathrm{~mm}$.

It can be seen that the extreme values of the loading change a lot with the cutwater clearence.

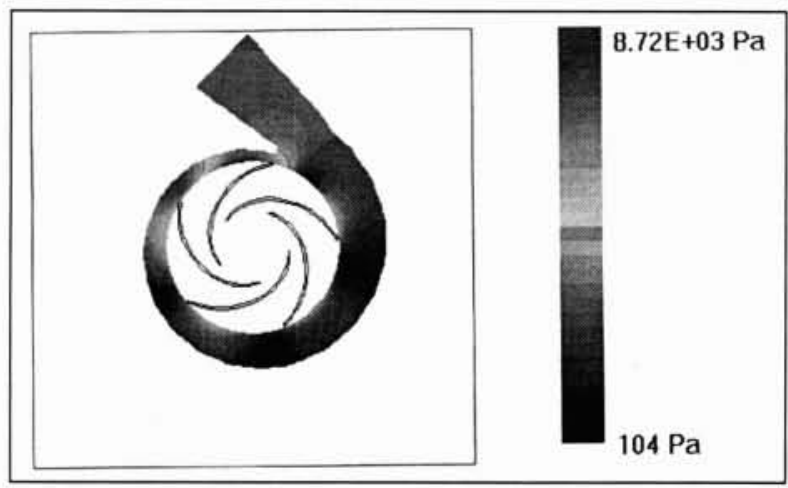

15. Amplitude of the first harmonic of pulsations in the water pump.

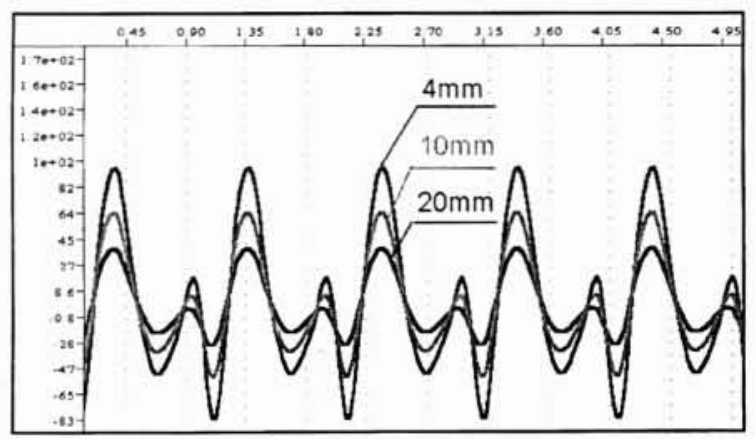

16. Tangential dynamic load $[N]$ on the cutwater.

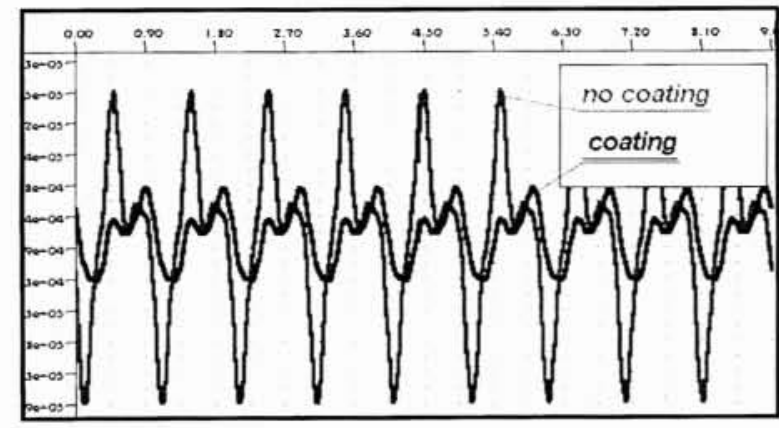

14. Coating effect at the pump exit.

\section{VII $\square$ CONCLUSIONS}

Exit impedance conditions affects mainly pressure pulsation in the pump diffuser. The same result is obtained for the influence of a damping coating of the diffuser wall.

The dynamic load on the cutwater depends much on the spacing between the impeller and the cutwater.

\section{REFERENCES}

[1] D. Dourneau A., Veigne-Leukam A., Barrand J.-P., CAIGNAERT G. (1992). - Effect of the line on the pressure fluctuations in the impeller and the scroll of a centrifugal pump tested with air. Fan noise. An International INCE Symposium, Senlis, France. CETIM.

[2] HaRmony M.K. I. (1997), - Software package for pressure fluctuation analysis in the volute casing of a centrifugal pump. Theoretical manual and users' guide. IRI/CETIM.

[3] TourRet J. (1991). - Hydraulic Noise Generation Studies in Centrifugal Turbomachine Through Visualization of the Non Stationary Pressure Field in the Volute and in the Impeller. ASME/Reprinted From FED, Vol. 128, Experimental and Numerical Flow Visualization. Editors : B. Khalighi etc./Book No.

[4] Timouchev S.F., IlLichov K.P., Koshelev L.M. (1997). Numerical and experimental study of pressure pulsation in highspeed LPRE centrifugal stage. $4^{\text {th }}$ French Congress on Acoustics, Marseille, France.

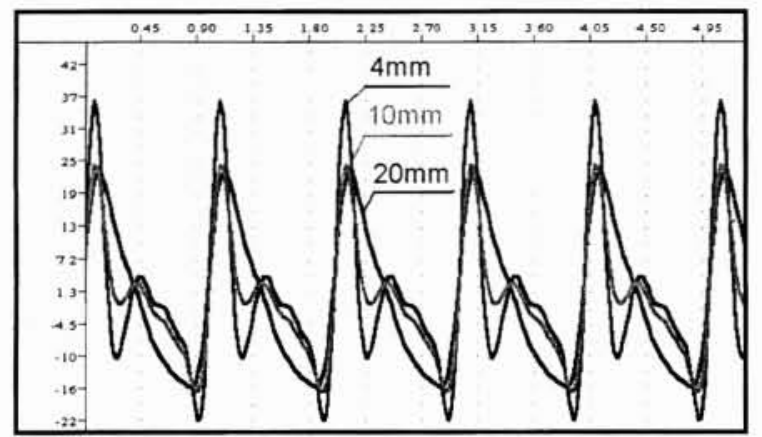

17. Radial dynamic load $[N]$ on the cutwater. 